- A periapical pocket cyst usually responds to root canal treatment.

- All the possible treatment modalities of a jaw lesion should be implemented before tooth extraction or any other surgical intervention.

- Always check whether the epithelial lining of the cyst is continuous with the root or not.

- Early diagnosis would save considerable worry and discomfort for the patient.

\title{
Paraesthesia of the lip and chin area resolved by endodontic treatment: A case report and review of literature
}

\author{
W. Jerjes, ${ }^{1}$ B. Swinson, ${ }^{2}$ B. Banu, ${ }^{3}$ M. Al Khawalde ${ }^{4}$ and C. Hopper ${ }^{5}$
}

Lower lip numbness is a symptom that may be due to entirely benign causes, or it may be the first sign of a more sinister problem. It has been reported as being the sole symptom of pathological lesions and metastatic tumours in the mandible.

We report a case of a middle-aged Caucasian male who presented with gradual onset of paraesthesia in the distribution of the mental nerve. Radiographic investigation revealed a lesion associated with the apices of the lower right premolar teeth. No surgical biopsy was taken and the patient was subsequently advised to undergo endodontic treatment of the lower right first and second premolar teeth.

Following root canal treatment there was improvement of the clinical symptoms and a gradual reduction in size of the periapical lesion on serial radiographs was clearly noted. A full resolution of symptoms was seen one year after the successful endodontic treatment. Working diagnosis of 'periapical pocket cyst' or 'bay cyst' was made on clinical, radiological findings. It is fair to suggest that this periapical lesion had directly or indirectly affected the inferior alveolar nerve causing it to be temporarily

\footnotetext{
${ }^{1 *}$ Honorary Lecturer in Oral and Maxillofacial Surgery; ${ }^{2}$ Specialist Registrar in Oral and Maxillofacial Surgery, Eastman Dental Institute; ${ }^{3}$ Specialist in Surgical Dentistry, Eastman Dental Institute; ${ }^{4} \mathrm{MSc}$ Student in Oral and Maxillofacial Surgery ${ }^{5}$ Consultant Oral and Maxillofacial Surgeon, Senior Lecturer, Head of Oral and Maxillofacial Department, Eastman Dental Institute.

${ }^{*}$ Correspondence to: Dr Waseem Jerjes, Department of Oral and Maxillofacial Surgery, Eastman Dental Institute for Oral Health Care Sciences, 256 Gray's Inn Road, London, WC1X 8LD

Email:waseem_wk1@yahoo.co.uk
}

\section{Refereed Paper}

Received 10.09.04; Accepted 10.01.05

doi: 10.1038/sj.bdj.4812412

๑ British Dental Journal 2005; 198: 743-745 dysfunctional which led to paraesthesia over the lip and chin area.

\section{CASE REPORT}

A 48-year-old man was referred by his general dental practitioner, following a gradual onset of paraesthesia in the distribution of the right mental nerve. History and clinical examination revealed no history of pain and nothing clinically of note save some heavily restored premolar teeth, one with amalgam, and the other with a composite resin restoration. Both teeth were very mildly tender to percussion and were found to be non-vital to an electrical pulp tester.

Radiographic examination showed a 7 to $8 \mathrm{~mm}$ (inverted ' $\mathrm{T}$ ' in shape) periapical cystic lesion in the area of the right mandibular premolars which was accompanied with widening of the periodontal membranes surrounding these teeth (Fig. 1). The area had a well-defined regular margin, extended beyond the mental foramen and was in close proximity to the inferior dental nerve in that area.

No surgical biopsy was undertaken and the working diagnosis of paraesthesia secondary to local pressure or inflammatory change effects of the periapical lesion made on clinical and radiolographic grounds. The patient then underwent successful endondontic treatment in the lower right premolars.

Review three months following endodontic treatment indicated that radiographi- cally, the lesion showed signs of resolution with a decrease in size and now showed two distinct cystic lesions concentrated around the apices of the first and second premolars (Fig. 2). The paraesthesia was still symptomatic to the patient though improving with time.

At subsequent review three months later, further reduction in size of lesions and good bone regeneration was observed at the superior border of the inferior dental canal. The lesions, though resolving were still in very close proximity to the mental foramen.

The third review six months later showed almost complete bony regeneration of the area with complete resolution of both lesions. The periodontal membranes of both teeth were shown to have completely regenerated (Fig. 3). The patient had also a complete recovery of sensation in the distribution of the right mental nerve.

\section{DISCUSSION}

Inflammatory cysts, most commonly radicular cysts, arise from the proliferation of the rests of Malassez within chronic periapical granulomas; factors determining cyst transformation mainly relate to the chronic inflammation following pulp necrosis, presence of microorganisms living in the apical root canal of affected teeth and the presence of cytokines containing growth factors that induce proliferation of the rests of Malassez. The 


\section{PRACTICE}

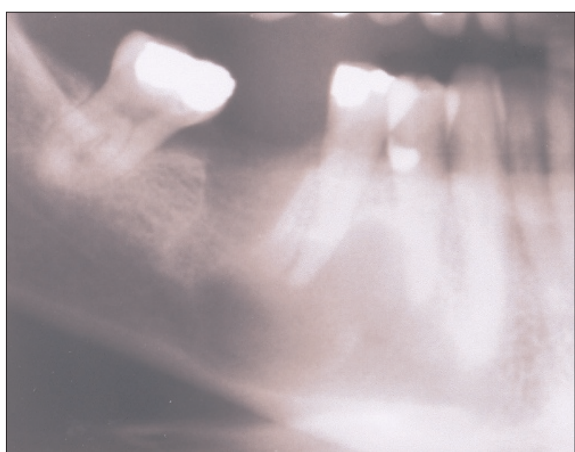

Fig. 1 Well-definied 'inverted-T in shape' periapical lesion

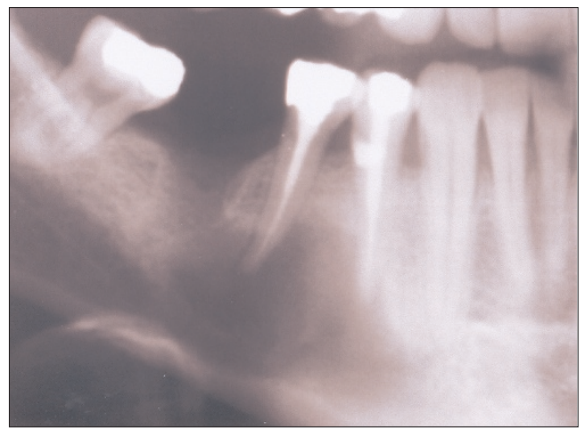

Fig. 2 The lesion showed signs of resolution following RCT

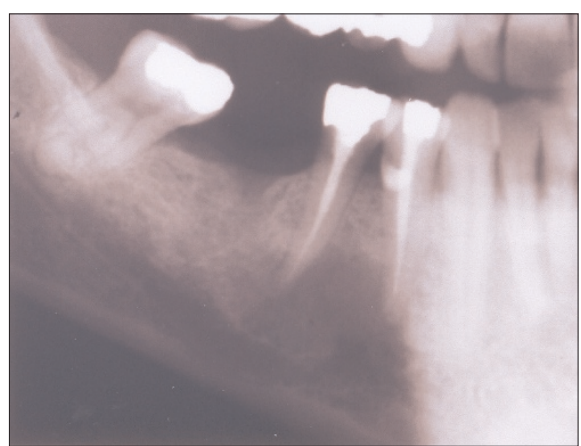

Fig. 3 Bone regeneration and complete recovery of sensation

mechanism of the formation of the cyst's lining epithelium is controversial but epithelial vascularity, release of toxic substances or enclavement by proliferating strands of epithelium might have a major role in the process. ${ }^{1,2}$

Studying the morphological aspect and the clinical relevance of some types of periapical cysts, led Simon ${ }^{3}$ to identify two different types of radicular cysts: 'true radicular cysts' represents cystic cavities completely lined by epithelium while the second type was called a 'bay cyst' where its epithelial lining opened to the canal of the affected tooth. If a true theory, this explains the reason behind the disappearance of some radicular cysts following root canal treatment. Unfortunately this theory was not confirmed by any other group of researchers and was challenged, since a clear relationship between the root

\begin{tabular}{|c|c|}
\hline Anaesthesia & Absence of all sensory modalities. \\
\hline Paraesthesia & $\begin{array}{l}\text { An abnormal sensation (tingling), } \\
\text { whether spontaneous or evoked. }\end{array}$ \\
\hline Dysaesthesia & $\begin{array}{l}\text { An unpleasant abnormal sensation, } \\
\text { whether spontaneous or evoked. }\end{array}$ \\
\hline Hyperaesthesia & $\begin{array}{l}\text { Increased sensitivity to stimulation, } \\
\text { excluding special senses. }\end{array}$ \\
\hline Hypoaesthesia & $\begin{array}{l}\text { Diminished sensitivity to stimulation } \\
\text { excluding special senses. }\end{array}$ \\
\hline
\end{tabular}

canal and the cyst epithelium was never proven. ${ }^{3}$

Nair et al. ${ }^{4}$ analysed the histology of 256 periapical specimens decalcified and embedded in plastic to determine the frequency of occurrence of abscess, granuloma and radicular cyst, and also to see if the two types of the radicular cyst do exist. The group observations showed that the incidence of radicular cyst among periapical lesions was low; the interesting finding was that $61 \%$ of the identified cysts fulfilled the criteria of true cysts and the rest were atypical and represented 'periapical pocket cysts'. The latter was described as an apical inflammatory lesion that contained a sac-like, epithelium lined cavity continuous with the root canal. This epithelium forms an attachment that seemed to seal off the infected root canal and its apical pouch from the periapical milieu; 5 so it was suggested that it is more appropriate to call this cyst a 'periapical pocket cyst' rather than a 'bay cyst'.

Therefore, this periapical lesion is more likely to heal following a good three dimensional root canal seal which eliminates the source of the infection that was the stimulus for propagation of the lesion. Working diagnosis of 'periapical pocket cyst' or 'bay cyst' was made on clinical, radiological findings; to fulfil the diagnostic criteria, a histopathology report should be included but we preferred to refer the patient for root canal therapy before undergoing any surgical intervention.

Sensory nerve disturbances (Table 1) of the orofacial region, especially paraesthesia of the lower lip can be a rare symptom. ${ }^{6-8}$

Pathological lesions, including periapical, ${ }^{9-12}$ periradicular dental infection, ${ }^{13}$ periodontal diseases ${ }^{14}$ and metastatic tumours like adenocarcinoma ${ }^{15}$ in the mandible are considered the main cause of paraesthesia in the lower lip. Lower lip numbness has also been reported in other circumstances such as periodontalendodontic pathosis, ${ }^{16}$ dental origin, ${ }^{17}$ following extraction, ${ }^{18}$ due to endodontic treatment, ${ }^{19}$ or following tooth restoration. ${ }^{20,21}$ Numbness has also been reported following implant placement, ${ }^{22}$ as part of

\begin{tabular}{ll} 
Table 2 Nerve Injury \\
\hline Neuropraxia & $\begin{array}{l}\text { Compression of the nerve with no } \\
\text { structural damage }\end{array}$ \\
Axonotmesis & $\begin{array}{l}\text { Rupture of axons within an intact } \\
\text { nerve sheath }\end{array}$ \\
Neurotmesis & $\begin{array}{l}\text { Complete severance of a peripheral } \\
\text { nerve }\end{array}$
\end{tabular}

orthodontic treatment, ${ }^{23}$ or orthognathic surgery, ${ }^{24}$ mainly for patients undergoing sagittal split osteotomy.

Systemic disease has been implicated in some instances such as multiple myeloma ${ }^{25}$ or lymphoma. ${ }^{26}$ Numbness has also been shown to develop following general anaesthesia. $^{27}$

Following endodontic treatment altered sensation may be due to the effects of filling material containing neurotoxic substances, such as paraformaldehyde, directly affecting the nerve. Directly injecting the endodontic filling material through the root apex and into the neurovascular canal is also a possibility.

The nerve injury or damage usually occurs in three forms (Table 2). Treating the cause will lead the nerve to regenerate in a short time especially following neuropraxia or axonotmesis which we think represents the type of injury in our case. The resolution of the paraesthesia in this case supports the theory that pressure caused by the expanding periapical lesion and the associated inflammatory responses caused the original symptom. Resolution in similar conditions has been reported following root canal treatment and periapical surgery. ${ }^{28}$

\section{CONCLUSION}

Sensory disturbances such as anaesthesia, dysaesthesia, hypoaesthesia, hyperaesthesia and paraesthesia may present in the oral cavity from many local and systemic causes. Inferior alveolar nerve paraesthesia is quite rare because of the unique anatomy of the nerve but its significance cannot be underestimated.

Careful clinical and radiographic diagnosis in this case followed by endodontic treatment proved to be successful in causing resolution of both the pathology and also the symptoms.

1. Ramachandran Nair P N. Light and electron microscopic studies of root canal flora and periapical lesions. J Endod 1987; 13: 29-39.

2. Nair P N, Sjogren U, Krey G, Kahnberg K E, Sundqvist $G$. Intraradicular bacteria and fungi in root-filled, asymptomatic human teeth with therapy-resistan periapical lesions: a long-term light and electron microscopic follow-up study. J Endod 1990; 16: 580-588.

3. Simon J H. Incidence of periapical cysts in relation to the root canal. J Endod 1980; 6: 845-8.

4. Ramachandran Nair P N, Pajarola G, Schroeder H E. Types and incidence of human periapical lesions obtained with extracted teeth. Oral Surg Oral Med Oral Pathol Oral Radiol Endod 1996; 81 : 93-102. 
5. Nair P N, Schroeder H E. Epithelial attachment at diseased human tooth-apex. J Periodontal Res 1985: 20: 293-300.

6. Flower E A, Yeung J. Lip numbness, sometimes a sinister symptom. Br Dent J 1989; 166: 46-48.

7. LaBanc J P. Epker B N. Serious inferior alveola nerve dysesthesia after endodontic procedure: report of three cases. J Am Dent Assoc 1984; 108: 605-7.

8. Jagger R G. Lip numbness - sometimes a sinister symptom. Br Dent J 1989; 166: 281-282.

9. Morse D R. Infection-related mental and inferior alveolar nerve paresthesia: literature review and presentation of two cases. J Endod 1997; 23: 457-460.

10. Di Lenarda R, Cadenaro M, Stacchi C. Paresthesia of the mental nerve induced by periapical infection: a case report. Oral Surg Oral Med Oral Pathol Oral Radiol Endod 2000; 90: 746-749.

11. Elliston N K, Hoen M M. Infectious transient dentalrelated paresthesia. Gen Dent 1996; 44: 66-69.

12. Giuliani M, Lajolo C, Deli G, Silveri C. Inferior alveolar nerve paresthesia caused by endodontic pathosis: a case report and review of the literature. Oral Surg Oral Med Oral Pathol Oral Radiol Endod 2001; 92: 670-674.

13. Ngeow W C. Lower lip numbness due to peri-radicular dental infection. Med J Malaysia 1998; 53:446-448.
14. Gilbert B O, Dickerson A W. Paresthesia of the mental nerve after an acute exacerbation of chronic apical periodontitis. J Am Dent Assoc 1981; 103: $588-590$

15. Rohrer M D, Colyer J. Mental nerve paresthesia: symptom for a widespread skeletal metastatic adenocarcinoma. J Oral Surg 1981; 39: 442-445.

16. Lambrianidis T, Molyvdas J. Paresthesia of the inferior alveolar nerve caused by periodontalendodontic pathosis. Oral Surg Oral Med Oral Pathol 1987; 63: 90-92.

17. Joubert J J, Farman A G, Nortje C J. Lip paresthesia of dental origin. J Oral Med 1979; 34: 26-27.

18. Gulicher D, Gerlach K L. Incidence, risk factors and follow-up of sensation disorders after surgical wisdom tooth removal. Study of 1,106 cases. Mund Kiefer Gesichtschir 2000; 4: 99-104.

19. Dempf R, Hausamen J E. Lesions of the inferior alveolar nerve arising from endodontic treatment. Aust Endod J 2000: 26: 67-71.

20. Abbott PV. Lower lip paraesthesia following restoration of a second premolar tooth. Case report. Aust Dent J 1997; 42: 297-301.

21. Zmener 0 . Mental nerve paresthesia associated with an adhesive resin restoration: a case report. $J$ Endod 2004; 30: 117-119.

22. Nazarian Y, Eliav E, Nahlieli O. Nerve injury following implant placement: prevention, diagnosis and treatment modalities. Refuat Hapeh Vehashinayim 2003; 20: 44-50, 101

23. Willy P J, Brennan P, Moore J. Temporary mental nerve paraesthesia secondary to orthodontic treatment - a case report and review. Br Dent J 2004; 196: 83-84.

24. Becelli R, Renzi G, Carboni A, Cerulli G, Gasparini G. Inferior alveolar nerve impairment after mandibular sagittal split osteotomy: an analysis of spontaneous recovery patterns observed in 60 patients. J Craniofac Surg 2002; 13: 315-320.

25. Reboiras Lopez M D, Garcia Garcia A, Antunez Lopez J, Blanco Carrion A, Gandara Vila P, Gandara Rey J $M$. Anaesthesia of the right lower hemilip as a first manifestation of multiple myeloma. Presentation of a clinical case. Med Oral 2001; 6: 168-172.

26. Ugboko V I, Ndukwe K C, Adelusola K A, Durosinmi M A. Burkitt's lymphoma presenting as lower lip paraesthesia in a 24 year old Nigerian. Case report. Aust Dent J 1999; 44: 58-60.

27. Azar I, Lear E. Lower lip numbness following general anesthesia. Anesthesiology 1986; 65: 450-451.

28. Borio PS, Giordano M, Mina M. Anesthesia in the chin area resolved by endodontic treatment. Minerva Stomatol 1984; 33: 465-468. 